\title{
Sciendo
}

DOI: $10.2478 /$ jolace-2020-0001

\section{Czech mothers read books to their young children: association with mothers' education}

\author{
Peter Gavora \\ Tomas Bata University in Zlín, the Czech Republic \\ gavora@utb.cz
}

\begin{abstract}
The study concentrated on mothers' reading to their preschool children. Three broad questions were posed about how the mother's educational level is associated with: (1) the mother's reasons to read to the child, (2) frequency and duration of this reading, (3) mother-child literacy interaction with the child. The sample of low education mothers $(n=55)$ and high education mothers $(n=213)$ was recruited to fill in a questionnaire of 46 items. Higher education mothers outperformed low education mothers in these variables: reading to the child in order to enhance cognitive development, appreciate the time they are with the child in reading sessions, reading to child frequency, and the number of books the child possesses. On the other hand, low education mothers more frequently than high education mothers ask children about book characters and explain reasons for reading.
\end{abstract}

Keywords: early literacy, reading to the child, home literacy environment, parent-child interaction

\section{Introduction}

The child's first encounters with literacy are in the home. Early literacy learning is efficient if the home environment is literacy-rich, i.e., if the child has access to children's books, magazines, letter games and other literacy materials and if parents frequently read books to their child and interact with the child over the books' content. The child's early literacy development is concurrent with, and supported by, oral language growth during the preschool years. Research indicates that oral language, phonological awareness, and print knowledge are the core components of a strong early literacy foundation (Whitehurst \& Lonigan, 1998).

\section{The home literacy environment}

The quality of the home literacy environment plays an important role in the development of early literacy of preschool children (Leseman \& De Jong, 1998; 
Roberts et al., 2005; van Steensen, 2006). The concept of the home literacy environment is rather broad, and authors vary as regards its elements. We emphasize three major components of this phenomenon: (a) the literacy resources in the home, (b) frequency and duration of parents' reading to the child, and (c) parent-child interaction in reading sessions.

To develop the language and literacy in preschool years, the child needs exposure to literacy resources (Sénéchal, 1997; Sénéchal et al., 1998; Hood et al. 2008). Literacy resources in the home are reading and writing materials available in the family. Primarily, they are children's story books, poems, picture books, encyclopaedias etc. The child also comes across adults' literature: books, "household literature" such as cookbooks or do-it yourself manuals, journals, advertising materials and brochures etc.

In addition to contacts with literacy resources, the child also needs to be immersed into literacy content. Children need to learn about the story inside the books, the setting and characters that shape the plot. This immersion is performed by the parent's readings to the child. Parents read to children on a number of opportunities, the most frequent one is the bed-side reading. The frequency and duration of parents' reading aloud to the child are factors that strongly influence the development of the child's language and literacy. It has been proved that if parents value and encourage literacy activities, such as engaging in shared reading with children and providing them reading materials, their children are likely to achieve higher level of school readiness, increase oral language development, and expand vocabulary (Durand, 2011; Farver al., 2013).

Parents-child interaction in reading sessions includes discussing over the book content. The parent reads a book to the child, points to pictures, explains unknown words, or clarifies the plot, context and characters. He/she discusses what happened in the story, evaluates the story characters or events, and described pictures. During this interaction, the child is exposed to complex sentence structures, world knowledge, and words that are not typically learned through dialogue and interactions with parents beyond the shared reading situations (Sénéchal et al., 1998; Martini \& Sénéchal, 2012).

Parents' reading is scarcely a one-way process, the child is not a quiet listener in a book reading session. The child actively responds to parents' stimuli, asks questions or comments on the story (Melissa-Halikiopoulou \& Natsiopolou, 2008; Korat et al., 2008). The child can also take initiative in home reading situations, pursue his/her own agenda and even control the parent's reading (Gavora, 2016).

\section{Mother's education and home literacy}

A body of studies identified that it is especially the mother's education that relates to frequency of reading to the child and the dialogue with the child over the 
book. In Australia, Torr (2004) found out that mothers with low level of education read books to children with very few questions aimed at the text content and they focussed on naming objects they saw in the book illustrations. The mothers' strategy was to read while letting the child listen quietly. Mothers with tertiary education provided children with opportunity to engage with the text by making inferences, generalizing, explaining, and asking questions about the text. In the Netherlands, Van Steensel (2006) categorized three levels of home literacy environments, i.e., rich, middling, and poor, and found that the mother's education strongly associated with these levels. As the level increased, the share of the rich home environment grew. The author emphasizes that though the level of mother's education is an important factor for the child's literacy development, many families with lower level of education value literacy for their children, read to children and discuss the books that were read. In a Greek study, MelissaHalikiopoulou and Natsiopolou (2008) observed parent-child dyads in reading sessions and reported 13 activities of mothers that were employed in their interactions while reading a book. The activities are, for instance, drawing the child's attention, explaining names, giving feedback, repeating the child's words and questioning to recall information. The authors identified the relationship between the mother's level of education and literacy strategies used by them. Mothers with tertiary education provided more challenging interactions with children over the book than did those with secondary education. The representative US survey (Yarosz \& Bartlett, 2001) documented that the frequency of shared reading reported by parents was predicted by maternal education (in addition to ethnicity, the language spoken in the home and the number of siblings).

Why do mothers with higher level of education read to their children more frequently and provide more demanding practicing in reading dyads to their preschool-age children than mothers with lower education? The research provided limited answers to this question. It may be hypothesized that higher educated mothers have stronger interests to improve intellectual abilities and skills of their children in general and literacy skills in specific. They may have stronger reasons to promote their children's attitudes to books and reading than mothers with lower education. Finally, they may have stronger interest to expand the knowledge of the world of their children than lower education mothers. These assumptions challenged the research in the study reported here, which is focused on a more detailed examination of association of mother's education with variables of reading to the child.

\section{The study}

The home literacy environment and parents' literacy practices with preschoolage children have been frequently investigated in at-risk families, for instance in 
ethnic minorities (Van Steensel, 2006; Hammer et al., 2007; Farver al., 2013) or low-income families (Jarret et al., 2015). Contrary to it, little is known about home literacy environment in rather homogenous localities (an exception: Hindman \& Morrison, 2012). Such research might reveal details that make the understanding of home literacy more refined. This was a motive to investigate mothers' reading to children in the mainstream population in the Czech Republic.

The specific focus of this study is to associate the mother's level of education with three broad home reading variables:

- The mother's reasons to read to the child.

- Frequency and duration of the mother's reading to the child.

- Mother-child literacy practices with the child.

Four hypotheses were formulated to test the relationships between the level of the mother's education and literacy variables. All of them assume that mothers with high education outperform their counterparts with lower education:

Hypothesis 1: High education mothers express more favourable reasons to read to their children than low education mothers.

Hypothesis 2: High education mothers read to their children more frequently than low education mothers.

Hypothesis 3: High education mothers have longer reading sessions with their children than low education mothers.

Hypothesis 4: High education mothers have more frequent literacy practices with their children than low education mothers.

\section{The sample}

The sample consists of 274 parents of preschool-age children who live in the Moravian part of the Czech Republic. These parents are from localities of three sizes, i.e., a village $(n=34)$, a small town $(n=78)$ and a city $(n=162)$. Participants were approached through preschools that were attended by their children. The majority of participants were female (89.2\%). Most of them live in two-parents families $(83.3 \%)$. They had one child $(66.2 \%)$, two children $(32 \%)$ or three children (1.9\%). These children were girls (44.1\%) or boys (56\%). The average age of children, which the respondents described in the questionnaire, was 53.3 months (SD 12.1). The children's age span was from 24 to 84 months.

For the purposes of the analysis of the association of mothers' education with reading variables, we divided mothers into two groups: low education mothers and high education mothers. The former group consists of ISCED-2011 categories Nos. 1, 2 and 3 (but not 344). The latter group is composed of ISCED categories Nos. $344,6,7$, and 8 . The sizes of two groups differ considerably. The number of low education mothers is 55 , the number of high education mothers is 213 . 


\section{The instrument}

A questionnaire about the home literacy environment was developed, which was inspired by Boudreau (2015) and Hindman \& Morrison, (2012) to serve this study. It consisted of 46 items divided in four components. The demographic component concerned respondents' and family members' gender, education, profession, family income, and number of children and age of children. The component dealing with mother's reasons to read to the child focused on cognitive, emotional, attitudinal and appeasing motives (13 items, reliability computed with Cronbach's Alpha $=0.870$ ). An example of an item: "I read to my child to expand the child's vocabulary". Respondents answered on five point scales ranging from never (1) to very frequently (5).

The component concerning the child's exposure to reading in the family had six items, concentrating on the number of children's books, opportunity to see parents reading for themselves, frequency and duration of mother's reading to the child, child's age at the beginning of reading by the mother, and years span of mother's reading to the child. An example of an item: "How frequently do you read to your child? (a) never/occasionally, (b) once a month, (c) once a week, (d) several times a week, (e) every day". Because of varied format of items, reliability computation of this component was not possible.

The component concerning mother's literacy practices with the child consisted of nine items (Cronbach's Alpha $=0.684$ ) and asked about mother-child discussions on book vocabulary, story context, story characters, connection of the content with real-life situations, and the mother's explanation of reasons to read to the child. Other items concerned mother's playing word, letter or number games with the child, and singing songs with the child. An example of an item: "How frequently do you ask questions about story characters (e.g., how he/she liked them)?" Respondents answered on five point scales ranging from never (1) to very frequently (5).

The questionnaires were filled in the respondents' homes. Anonymous answers were required in order to protect their privacy as well as to increase truthfulness of the answers.

\section{Statistical procedures}

Interval variable results were expressed as arithmetic averages and standard deviations. Ordinal variable results were expressed as percentages of occurrence. Statistical differences between variables were computed with Mann-Whitney U test. In accord with APA recommendations, significance level was expressed by the exact value of $p$, not as $p<0,01$ or $p<0,05$. Reliabilities of questionnaire components were computed with Cronbach's Alpha. 


\section{Results}

First, the mother's reasons to read are discussed, followed by child's exposure to reading in the family and by mother's literacy practices with the child.

Mothers' reasons of reading to their children is the essence of their attitudes to and values of home literacy. If mothers have no reason they probably consider reading to their child a waste of time and do not read. Table 1 shows averages of 13 items that concern the mothers' reasons to read to the child, as categorised by the mothers' level of education.

The first two items relate to emotional reasons. Mothers of both groups place much emphasis on emotional reasons of reading - the averages are much above the midpoint of the five-point scale used. However, high education mothers appreciate more strongly their reading sessions with the child. Contrary to this, there were no statistical differences between the two education groups in mothers' enjoyment of reading with the child. A surprising finding is that neither group outperformed the other in forming the child's favourable attitudes to books (item 3). However, the averages in attitudinal reasons to read in both groups are high, which indicate positive appreciation of books.

The questionnaire has six items that concern cognitive reasons of reading to the child (items $4-9$ ). They cover a range of aspects of promotion of the child's intellectual abilities and skills: expansion of vocabulary, promotion of imagination and memory, reasoning, learning life lessons, and expanding the knowledge about the world. In this component of the questionnaire, distinct dominance of high education mothers over those with low education was detected. Five items, out of six, showed significant differences in favour of high education mothers. The only item that avoided this trend was teaching about life in the book content (item 8). Overall, mothers with high education hold strong cognitive reasons of reading to the child. They consider it important for the children's intellectual development and learning. As expected, there was no difference between the two groups in reading to the child as a way of preparation for primary school (item 10). The averages are smaller than in other items. Mothers apparently regard primary education as a faraway target and do not place much emphasis on it in the preschool age.

Items 11 and 12 required the respondents to rate their reasons to read for appeasing the child and wanting the child to fall asleep. Again, as expected, there was no statistical difference between the two groups in these items. The averages are rather low, and in the case of making the child sleep they are even lower. However, high education mothers have stronger reasons to read to the child even if they are tired (item 13). The usual time for a reading session with the child is in the evening. Mothers must concentrate their will and power to overcome the 
burden of the day's work and make the reading possible and pleasant. Low education mothers ten to have physically more demanding jobs so they are more tired in the evening and thus are less inclined to read to children than are higher education mothers.

The aggregated results of the 13 items concerning reasons to read to the child show large differences between the two groups (Table 1, bottom row). The difference is statistically significant. Thus Hyp. 1 was supported. Generally, mothers with higher education have stronger motives than their counterparts in the low education group in decisions to read to their children. They place much emphasis on literacy values and demonstrate that their engagement to reading to children is a wealth that will bring its fruits in the child's literacy development. This does not claim that mothers with lower education abandon reading to their children. Rather, it witnesses that their reasons are not so strong as are those with mothers in the high education group.

Tab. 1: Reasons to read to the child in the low and high mother's education groups

\begin{tabular}{|l|l|l|l|l|l|l|}
\hline \multirow{2}{*}{ Mother's reasons to read } & \multicolumn{2}{c|}{$\begin{array}{c}\text { Low education } \\
\text { mothers }\end{array}$} & \multicolumn{2}{c|}{$\begin{array}{c}\text { High education } \\
\text { mothers }\end{array}$} & \multirow{2}{*}{ Sign. } \\
\cline { 3 - 6 } & $\mathrm{n}$ & $\mathrm{M}(\mathrm{SD})$ & $\mathrm{n}$ & $\mathrm{M}(\mathrm{SD})$ & \\
\hline 1 & appreciate to be with child & 54 & $3.91(1.12)$ & 211 & $4.23(1.02)$ & $\mathbf{0 . 0 3 4}$ \\
\hline 2 & brings joy to parent & 53 & $4.36(0.81)$ & 211 & $4.27(0.91)$ & 0.642 \\
\hline 3 & attitude to books & 53 & $4.19(0.96)$ & 213 & $4.36(0.90)$ & 0.191 \\
\hline 4 & vocabulary expansion & 53 & $4.34(0.96)$ & 212 & $4.67(0.68)$ & $\mathbf{0 . 0 0 8}$ \\
\hline 5 & imagination promotion & 53 & $4.19(0.96)$ & 213 & $4.46(0.82)$ & $\mathbf{0 . 0 0 3}$ \\
\hline 6 & memory promotion & 54 & $4.39(0.86)$ & 212 & $4.68(0.69)$ & $\mathbf{0 . 0 0 4}$ \\
\hline 7 & reasoning promotion & 53 & $4.11(1.05)$ & 212 & $4.53(0.79)$ & $\mathbf{0 . 0 0 6}$ \\
\hline 8 & teaching abut life & 54 & $4.02(1.14)$ & 212 & $4.29(0.89)$ & 0.158 \\
\hline 9 & expand world knowledge & 53 & $4.14(0.96)$ & 213 & $4.46(0.82)$ & $\mathbf{0 . 0 3 6}$ \\
\hline 10 & $\begin{array}{l}\text { preparation for } \\
\text { school }\end{array}$ & 54 & $3.76(1.26)$ & 212 & $3.75(1.24)$ & 0.913 \\
\hline 11 & calm down child & 55 & $2.95(1.21)$ & 213 & $3.05(1.30)$ & 0.653 \\
\hline 12 & make child sleep & 54 & $2.78(1.38)$ & 213 & $2.77(1.37)$ & 0.954 \\
\hline 13 & even if parent tired & 51 & $3.33(1.35)$ & 212 & $3.76(1.22)$ & $\mathbf{0 . 0 3 7}$ \\
\hline Overall reasons to read & 47 & $3.87(0.64)$ & 209 & $4.12(0.57)$ & $\mathbf{0 . 0 0 9}$ \\
\hline
\end{tabular}

Notes: The quantity of the respondents in items varies due to missing data. $\mathrm{M}=$ average; $\mathrm{SD}=$ standard deviation; Sign. = statistical significance as computed with Mann-Whitney $U$ test of differences. Numbers in bold indicate significant differences between the groups.

\section{Child's exposure to reading in the family}


Frequency and duration of reading to the child are generally considered the key characteristics of home literacy practices. Table 2 shows the basic findings. About $41 \%$ of high education mothers read to their child every day, while only a quarter of low education mothers does it. About equal percentage (44\%) of mothers read to the child several times a week. Overall, the difference in frequency of reading to the child between the two groups is statistically significant in favour of the high education mothers. Thus Hyp. 2 was supported. In addition to the frequency of reading to the child accomplished by the first parent (typically the mother), we also examined how frequently another person in the household reads to the child (typically, a father or a grandparent). No statistically significant difference was detected.

Table 2 shows also no statistically significant differences between the two groups in the duration of the mother's reading session with the child. Thus Hyp. 3 was rejected. Most respondents read to the child for 10-15 minutes. Longer reading times are somewhat less frequent. If the reading session is organized effectively, especially if it includes the mother's interaction with the child about the book content, then the benefits are valuable even if the reading session is only 15 minutes long. However, longer reading sessions bring more benefits.

Because the child's age may affect the frequency and duration of reading to the child, it was inspected whether or not it was the age and not the mother's education that made the difference. However, no statistical difference was revealed in children's age between the groups $(U=500.5, p=0.482)$. We also examined whether of not it is the mother's marital status that made the difference in reading frequency and reading duration. It can be assumed that in single parent families the mother has less time for reading because she must do all the household duties alone. In single parent families there were no statistical differences between the two education groups in reading frequency $(U=143, p=$ $0.53)$ or reading duration $(U=178, p=0.221)$. However, the number of single families in the sample was small (17 in the mother's low education group and 26 in the mother's high education group), which may distort the findings.

Finally, we examined the association of mother's education and the number of books their children have. Possessing book is an important factor of the home literacy environment. It helps shaping the child's attitude to books and literacy in general. The results show that mother's education is strongly associated with the number of books the child has. In the average, children of mothers with higher education have more books than mothers with low education group. The difference is statistically significant. Mothers with higher education usually have higher level jobs and higher income than other mothers. This affords them to buy more children's books. The correlation between mother's education and mother's 
level of profession is rather high $\left(\mathrm{r}_{\mathrm{rho}}=0.630^{* *}\right)$, the correlation with income is lower $\left(\mathrm{r}_{\mathrm{rho}}=0.353^{* *}\right)$.

Tab. 2: Child's exposure to reading in the family in low and high mothers' education groups

\begin{tabular}{|c|c|c|c|c|c|c|c|c|}
\hline & & & $\begin{array}{l}\text { Never/ } \\
\text { occasion } \\
\text { ally }\end{array}$ & $\begin{array}{l}\text { Once } \\
\text { a month }\end{array}$ & $\begin{array}{l}\text { Once } \\
\text { a week }\end{array}$ & $\begin{array}{l}\text { Several } \\
\text { times } \\
\text { a week }\end{array}$ & $\begin{array}{l}\text { Every } \\
\text { day }\end{array}$ & Sign. \\
\hline \multirow[t]{2}{*}{14} & \multirow{2}{*}{$\begin{array}{l}\text { Reading to } \\
\text { child frequency }\end{array}$} & LEM & $3.8 \%$ & $7.7 \%$ & $19.2 \%$ & $44.2 \%$ & $25 \%$ & \multirow{2}{*}{0.007} \\
\hline & & HEM & $1 \%$ & $3.9 \%$ & $10.6 \%$ & $44 \%$ & $40.6 \%$ & \\
\hline \multirow[t]{2}{*}{15} & \multirow{2}{*}{$\begin{array}{l}\text { Reading to } \\
\text { child by other } \\
\text { adult }\end{array}$} & LEM & $21.2 \%$ & $23.1 \%$ & $21.2 \%$ & $26.9 \%$ & $7.7 \%$ & \multirow[b]{2}{*}{0.398} \\
\hline & & HEM & $15.3 \%$ & $23 \%$ & $23 \%$ & $30.6 \%$ & $8.1 \%$ & \\
\hline \multirow[t]{3}{*}{16} & \multirow[t]{3}{*}{$\begin{array}{l}\text { Duration of a } \\
\text { reading session }\end{array}$} & & $5 \mathrm{~min}$. & $\begin{array}{l}\text { 10-15 } \\
\text { min. }\end{array}$ & 20 min. & 30 min. & $\begin{array}{l}40 \\
\text { min. }\end{array}$ & \\
\hline & & LEM & $5.8 \%$ & $55.8 \%$ & $34.6 \%$ & $1.9 \%$ & $1.9 \%$ & \multirow{2}{*}{0.189} \\
\hline & & HEM & $1.9 \%$ & $50.2 \%$ & $45 \%$ & $2.9 \%$ & $0 \%$ & \\
\hline \multirow[t]{3}{*}{17} & \multirow{3}{*}{$\begin{array}{l}\text { Number of } \\
\text { children's } \\
\text { books }\end{array}$} & & 5 & 10 & 20 & 30 & $30+$ & \\
\hline & & LEM & $3.7 \%$ & $11.1 \%$ & $38.9 \%$ & $22.2 \%$ & $24.1 \%$ & \multirow[t]{2}{*}{0.000} \\
\hline & & HEM & $0.9 \%$ & $6.2 \%$ & $15.2 \%$ & $22.7 \%$ & $55 \%$ & \\
\hline
\end{tabular}

Note: LEM = low education of mother, HEM = high education of mother. Sign. $=$ statistical significance as computed with Mann-Whitney U test of differences. Numbers in bold indicate significant differences between the groups.

The age at the onset of the mother's reading to the child is a factor that is strongly associated with many reading achievement variables. If the parent reads to their children in early stage, they probably become good readers themselves. In our sample, low education mothers started to read to their children at 18 months, while higher education mothers began it when the child was 12 months old. The difference is statistically significant $(U=4123, p=0.002)$ in favour of high education mothers. Parents who read from early age bring to their children an advantage of a long period of literacy and language input. This was also documented in the study of Niklas et al. (2016), who summed up their findings metaphorically: "Early birds catches the worm". However, in this study, no statistical difference was found in exposition of reading to the child, which was computed as the child's age of the beginning to read to the child subtracted from the child's current physical age $(U=4459.5, p=0.140)$. This indicates that it is not the length of the reading input but the developmental time when the reading to the child begins, which distinguishes low and high education mothers. 


\section{Mother's literacy practices with the child}

Literacy practices are activities the mother organizes and performs with the child. They concern both the use of the book features and activities beyond the book itself (e.g., playing letter games with the child). Table 3 brings findings about nine of such activities. They all are relevant components of mother-child interaction with the child because they bring more effective cognitive stimulation to the child than sheer reading aloud.

In both mothers' education groups the averages are somewhat smaller than those of the mothers' reasons to read to the child. This is obvious. Doing these activities is more demanding for the mother than answering questionnaire items about the motives to read to the child. Asking questions, explaining the story plot, persuading the child of importance of reading, etc. are difficult tasks for the mother. Mother-child interaction is challenging and requires mother's sensitive responding to the child's reactions. In addition, doing effective interaction over the book requires certain knowledge and skills on the side of mothers. This explains somewhat lower self-rating on the literacy practices items.

Aggregated items of the mothers' literacy practices (Table 3, bottom row) show no statistical difference between the two mothers' education groups. Thus Hyp. 4 was rejected. The finding that mothers in both education groups do not differ in literacy practices with their children was a surprising one because we had assumed that high education mothers would be more frequently engaged in these demanding activities. However, this assumption did not prove right. The scores on individual literacy practices reveal more details.

Only two types of practices show statistical differences between the two mothers' educational groups, and they are in favour of low education mothers. This violated another assumption. These mothers scored better than their counterparts in the high education group in discussing the book characters (item 20). This activity is an essential feature for understanding the story plot. Asking children about the book heroes is a basic strategy that the mother follows in a reading session. High education mothers probably do not need to check frequently whether the child knows who are the heroes or what actions they take as low education mothers do. This clarifies the difference between the two mothers' education groups. Explaining the reasons for reading (item 23) is probably necessary in families where the literacy culture is not very rich but not in families where the child sees parents reading for enjoyment or pleasure frequently. The later occurs more probably in families with high education mothers.

Notes - Tab 3: The number of respondents vary in items due to missing data. EM= education of mother. $M=$ average; $S D=$ standard deviation; Sign. = statistical 
significance as computed with Mann-Whitney $U$ test of differences. Numbers in bold indicate significant differences between the groups

Tab. 3: Mother's literacy practices with the child

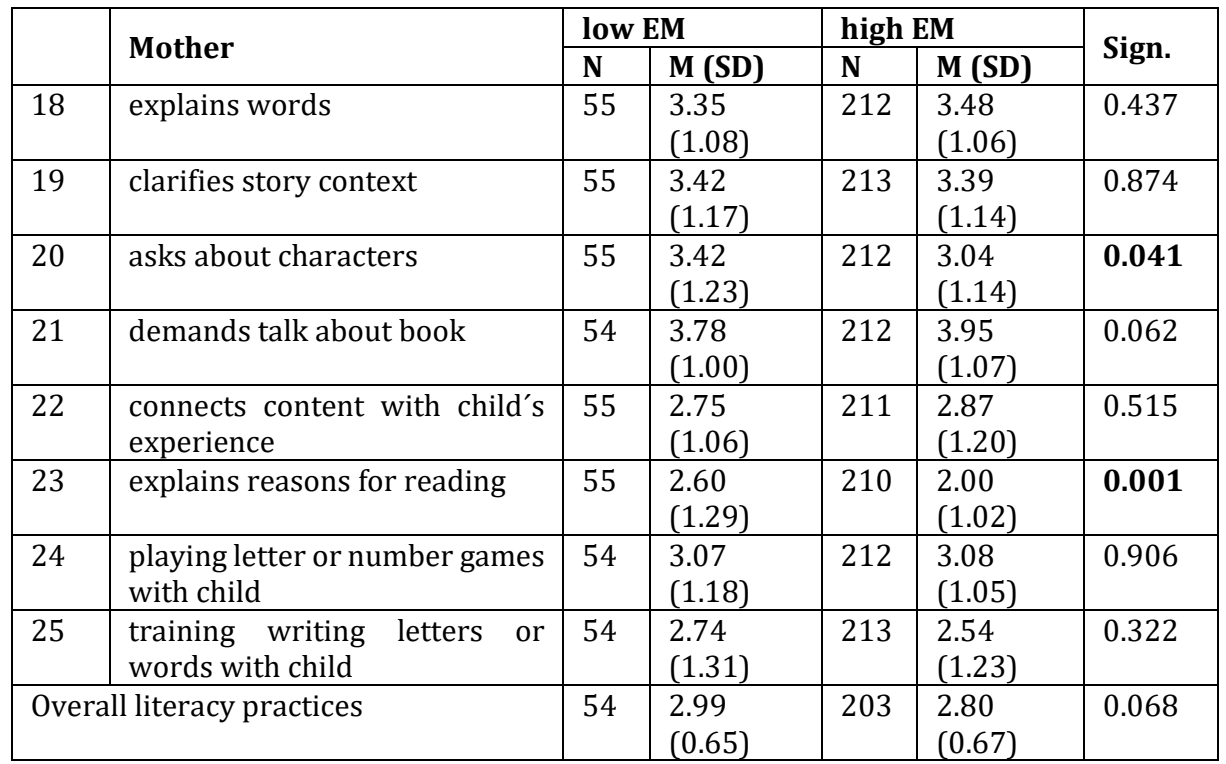

\section{Discussion}

The purpose of the study was to examine the relationship between mothers' education and reading books to their preschool children. The data reveal that the higher education mothers justify this reading especially for cognitive reasons (expansion of the child's knowledge, vocabulary, reasoning, imagination) and emotional reasons. This confirms the findings of other studies (DeBaryshe, 1995; Wiegel, Martin, \& Bennett, 2006) that - in addition to mothers' level of education it is the mothers' beliefs in the value of book reading and in the child's experiences with books that is important in the development of the child's literacy. The data show that the higher education mothers justify reading to the child especially for cognitive reasons (expansion of the child's knowledge, vocabulary, reasoning, imagination) and emotional reasons.

The findings indicate that higher education mothers establish higher quality home literacy environment than do lower deduction mothers. In this study these mothers began to read to the child earlier and read to them more frequently than low education mothers do. This does not say that low education mothers neglect 
the literacy development of their children in the preschool age. In the average, most of them read to the child several times a week and each reading session takes up to ten minutes. However, their children have considerably fewer books than those of higher education mothers.

Surprisingly, there was no difference in book-based interactions between the two mothers' education groups (except in discussing the book characters and explaining the reasons to read to the child). This is in contrast to other studies that showed that mothers' education has a close association with theses interactions (Raikes et al., 2006; Suizzo \& Stapleton, 2007). The disparity can be explained by differences between Czech and American samples and/or by research instruments used.

A favourable result is that regardless of education level, mothers engage in dialogic communication with children over the book content. The data indicate that shared reading in most of the respondents' families is not a one-way process. The child is a partner in the book-related communication.

As any research, also this one has limitations. All findings are based on the data gathered by a self-rate instrument. The respondents' responses are declarations rather than pictures of their actual behaviour in reading sessions with the child. In addition, the sample was too small and non-random to consider the results to be representative of mothers with preschool children in the Czech Republic. Nevertheless, the data are rich and contribute to better understanding of the literacy development of preschool children in the family.

\section{References}

Boudreau, D. (2015). Use of parent questionnaire in emergent and early literacy assessment of preschool children. Language, Speech, and Hearing Services in Schools, 36(1), 33-47. htps://doi.org/10.1044/0161-1461(2005/004)

DeBaryshe, B. D. (1993). Joint picture-book reading correlates of early oral language skill. Journal of Child Language, 20, 455-462. https://doi.org/10.1017/s0305000900008370

Durand, T. M. (2011). Latino parental involvement in kindergarten: Findings from the Early Childhood Longitudinal Study. Hispanic Journal of Behavioral Sciences, 33(4), 469-489. https://doi.org/10.1177/0739986311423077

Farver, J.A., Xu, Y., \& Lonigan, C. J., \& Eppe, S. (2013). The home literacy environment and Latino head start children's emergent literacy skills. Journal of Developmental Psychology, 49(4), 775-791. https://doi.org/10.1037/a0028766

Gavora, P. (2016). Preschool children in book-reading situations with parents. The perspective of personal agency theory. Studia Paedagogica, 21(4), 99-116. https://doi.org/10.5817/sp2016-4-5 
Hammer, C. Sch., Rodrigues, B. L., \& Lawrence, F R. (2007). Puerto Rican mothers' beliefs and home literacy practices. Language, Speech and Hearing Services in Schools, 38(3), 216-224. https://doi.org/10.1044/0161-1461(2007/023)

Hindman, A. H. \& Morrison, F. J. (2012). Differential contribution of three parenting dimensions to preschool literacy skills in a middle-income family. MerrillPalmer Quarterly, 58(2), 191-223. https://doi.org/10.1353/mpq.2012.0012

Hood, M., Conlon, E., \& Andrews, G. (2008). Preschool home literacy practices and children's literacy development: A longitudinal analysis. Journal of Educational Psychology, 100(2), 252-271. https://doi.org/10.1037/0022-0663.100.2.252

Jarret, R. L., Hamilton, M.-B., \& Coba-Rodrigues, S. (2015). „So we would all help pitch in." The family literacy practices of low income African American mothers of preschoolers. Journal of Communication Disorders, 57, 81-93. https://doi.org/10.1016/j.jcomdis.2015.07.003

Korat, O., Ron, R., \& Klein, P. (2008). Cognitive mediation and emotional support of fathers and mothers to their children during shared book-reading in two different SES groups. Journal of Cognitive Education and Psychology, 7(2), 223247. https://doi.org/10.1891/194589508787381872

Leseman, P., \& de Jong, P. F. (1998). Home literacy: Opportunity, instruction, cooperation and social-emotional quality predicting early reading achievement. Reading Research Quarterly, 33(3), 294-318. https://doi.org/10.1598/rrq.33.3.3

Martini, F., \& Sénéchal, M. (2012). Learning literacy skills at home: Parent teaching, expectations, and child interest. Canadian Journal of Behavioural Science / Revue canadienne des sciences du comportement, 44(3), 210-221. https://doi.org/10.1037/a0026758

Melissa-Halikiopoulou, Ch., \& Natsiopolou, T. (2008). Mothers reading children's books to preschoolers. A Greek study. International Journal of Caring Sciences, 1(2), 74-78. https://doi.org/10.2139/ssrn.2781839

Niklas, F., Cohrssen, C., Tayler, C., \& Schneider, W. (2016). Erstes Vorlesen: Der Früher Vogel fängt den Wurm. Zeitschrift für Pädagogische Psychologie, 30(1), 35-44. https://doi.org/10.1024/1010-0652/a000166

Raikes, H., Luze, G., Brooks-Gunn, J. et al. (2006). Mother-child bookreading in lowincome families: Correlates and outcomes during the first three years of life. Child Development, 77, 924-953.

Roberts, J., Jergens, J., \& Burchinal, M. (2005). The role of home literacy practices in preschool children's language and emergent literacy skills. Journal of Speech, Language, and Hearing Research, 48(2), 345-359. https://doi.org/10.1044/1092-4388(2005/024) 
Sénéchal, M. (1997). The differential effect of storybook reading on preschoolers' acquisition of expressive and receptive vocabulary. Child Language, 24, 123138. https://doi.org/10.1017/s0305000996003005

Sénéchal, M., LeFevre, J.-A., Thomas, E. M., \& Daley, K. E. (1998). Differential effects of home literacy experiences on the development of oral and written language. Reading Research Quarterly, 33(1), 96-116. https://doi.org/10.1598/rrq.33.1.5

Suizzo, M., \& Stapleton, L. M. (2007). Home-based parental involvement in young children's education: Examining the effects of maternal education across U.S. ethnic groups. Educational Psychology, 27, 533-556. https://doi.org/10.1080/01443410601159936

Torr, J. (2004). Talking about picture books: The influence of maternal education on four-year-old children's talk with mothers and pre-school teachers. Journal of Early Childhood Literacy, 4(2), 181-210. https://doi.org/10.1177/1468798404044515

Van Steensel, R. (2006). Relations between socio-cultural factors, the home literacy environment and children's literacy development in the first years of primary education. Journal of Research in Reading, 29(4), 367-382. https://doi.org/10.1111/j.1467-9817.2006.00301.x

Whitehurst G. J. \&, Lonigan C. J. (1998). Child development and emergent literacy. Child Development, 69(3), 848-872. https://doi.org/10.1111/j.14678624.1998.tb06247.x

Wiegel, D. J., Martin, S. S., \& Bennett, K. K. (2006). Mothers' literacy beliefs: Connections to the home literacy environment and preschool children's literacy development. Journal of Early Childhood Literacy, 6(2), 191-211. http: doi/10.1177/1468798406066444

Yarosz, D.J. \& Barnett, W.S. (2001). Who reads to young children?: Identifying predictors of family reading activities. Reading Psychology, 22(1), 67-81. https://doi.org/10.1080/02702710121153

\section{Contact}

prof. PhDr. Peter Gavora, CSc.

Department of School Pedagogy

Faculty of Humanities

University of Tomas Bata in Zlín

Štefánikova 5670

76001 Zlín

Czech Republic

gavora@utb.cz 